\title{
Potential of airborne hyperspectral data for geo-exploration over parts of different geological/metallogenic provinces in India based on AVIRIS-NG observations
}

\author{
Satadru Bhattacharya ${ }^{1, *}$, Hrishikesh Kumar ${ }^{1}$, Arindam Guha ${ }^{2}$, \\ Aditya K. Dagar ${ }^{1}$, Sumit Pathak ${ }^{1}$, Komal Rani (Pasricha) ${ }^{2}$, S. Mondal ${ }^{3}$, \\ K. Vinod Kumar ${ }^{2}$, William Farrand ${ }^{4}$, Snehamoy Chatterjee ${ }^{5}$, S. Ravi ${ }^{6}$, \\ A. K. Sharma ${ }^{1}$ and A. S. Rajawat ${ }^{1}$ \\ ${ }^{1}$ Space Applications Centre, Indian Space Research Organisation, Ahmedabad 380 015, India \\ ${ }^{2}$ National Remote Sensing Centre, Indian Space Research Organisation, Hyderabad 500 042, India \\ ${ }^{3}$ Department of Geophysics, Indian Institute of Technology (ISM), Dhanbad 826 004, India \\ ${ }^{4}$ Space Science Institute, Boulder, Colorado 80301, USA \\ ${ }^{5}$ Department of Geological and Mining Engineering and Sciences, Michigan Technological University, Houghton, Michigan 49931, USA \\ ${ }^{6}$ Geological Survey of India Training Institute, Bandlaguda, Hyderabad 500068 , India
}

In this article, we discuss the potential of airborne hyperspectral data in mapping host rocks of mineral deposits and surface signatures of mineralization using AVIRIS-NG data of a few important geological provinces in India. We present the initial results from the study sites covering parts of northwest India, as well as the Sittampundi Layered Complex (SLC) of Tamil Nadu and the Wajrakarur Kimberlite Field (WKF) of Andhra Pradesh from southern India. Modified spectral summary parameters, originally designed for MRO-CRISM data analysis, have been implemented on AVIRIS-NG mosaic of Jahazpur, Rajasthan for the automatic detection of phyllosilicates, carbonates and Fe-Mg-silicates. Spectral analysis over
Ambaji and the surrounding areas indicates the presence of calcite across much of the study area with kaolinite occurring as well in the north and east of the study area. The deepest absorption features at around 2.20 and $2.32 \mu \mathrm{m}$ and integrated band depth were used to identify and map the spatial distribution of phyllosilicates and carbonates. Suitable thresholds of band depths were applied to map prospective zones for marble exploration. The data over SLC showed potential of AVIRIS-NG hyperspectral data in detecting mafic cumulates and chromitites. We also have demonstrated the potential of AVIRIS-NG data in detecting kimberlite pipe exposures in parts of WKF.
Keywords: Data, geological provinces, host rocks, hyperspectral, mineral deposits.

\section{Introduction and background}

WITH the advent of hyperspectral remote sensors or imaging spectrometers, it is now possible to detect and quantify minerals, rocks and various other earth resource constituents $^{1-3}$. Imaging spectroscopy has also become an invaluable tool for remote compositional assessment of planetary bodies such as the Moon, Mars, asteroids, Jovian planets and comets ${ }^{4-9}$. Even though quite a few imaging spectrometers have been flown globally from aerial and space-borne platforms, in India the efforts towards developing hyperspectral sensors are relatively

\footnotetext{
*For correspondence. (e-mail: satadru@sac.isro.gov.in)
}

recent. The first Indian imaging spectrometers include Hyperspectral Imager (HySI) onboard Indian Mini Satellite-1 (IMS-1) for Earth observation and Chandrayaan-1 (refs 10,11) for lunar surface compositional mapping in 2004 and 2008 respectively.

In India, various researchers have utilized the remotely sensed hyperspectral data for identification of minerals and discrimination of rock types based primarily on the spectrally contiguous nature of the images acquired $^{12-16}$

As a prelude to a joint future space-borne hyperspectral mission between Indian Space Research Organisation (ISRO) and National Aeronautics and Space Administration (NASA), airborne hyperspectral imaging campaign is being conducted over different parts of India covering various scientific and application themes such as geology, agriculture, snow and glaciers, forestry, urban, coastal and atmospheric sciences and applications. Under this 


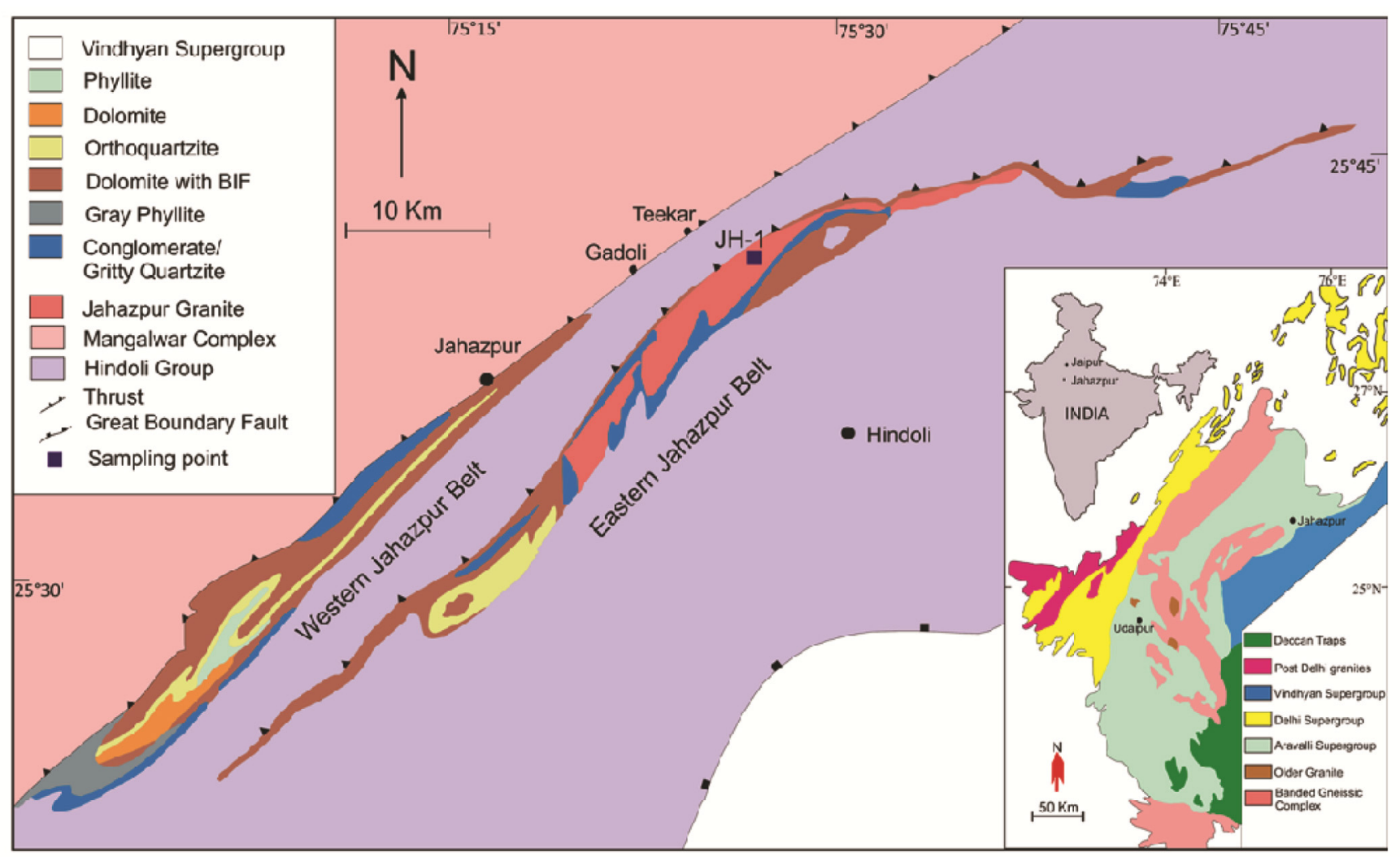

Figure 1. Geological map of Jahazpur, Rajasthan, modified by Dey et al. ${ }^{20}$ (after Pandit et al. ${ }^{21}$ ).

campaign, Airborne Visible-Infrared Imaging Spectrometer-Next Generation (AVIRIS-NG) instrument was flown over various parts of India having different types of geologic and tectonic milieu during January-March 2016, to carry out remote geochemical mapping of the study areas and delineation of potential future exploration targets within the studied regions ${ }^{17,18}$. Here we report the studies conducted over parts of Jahazpur mineralized belt of Rajasthan, Ambaji polymetallic sulphide belt of Gujarat, Sittampundi layered complex (SLC) of Tamil Nadu and Rishabhdev Ultramafic Complex of Rajasthan.

Our primary objective is to map diverse mineralogical and/or lithological entities present within the study areas based on spectral signature studies, which is otherwise not possible using a broad-band remote sensor, and to detect and map the hydrothermal alteration zones, gossans, etc. that are often associated with mineral/ore.

\section{Study areas and data used}

\section{Jahazpur}

This study area is situated in the southeastern part of the Aravalli craton and primarily represents a greenschist facies metasedimentary sequence sharing a thrusted contact with rocks of the Mangalwar complex in the northwest and separated from the Vindhyan sediments by the great boundary fault (GBF) of Rajasthan in the southeast $^{19}$. As previously suggested, the area mainly comprises litho-assemblages belonging to the Jahazpur Group and Hindoli Group ${ }^{20,21}$ (Figure 1). Detailed accounts on the rocks of Jahazpur belt can be found in the GSI Miscellaneous Publication ${ }^{22}$.

The Lower Proterozoic supracrustal rocks of the Jahazpur Group of Bhilawara Supergroup are known to have potential for base metal mineralization. The intracratonic-failed rifts of eastern and western Jahazpur belts represent a classic example of SEDEX-type base metal mineralization. The host rocks for base metal mineralization at Jahazpur include dolomite, dolomitic marble, carbonaceous phyllite, banded iron formation (BIF) and dolomite with BIF. Bedrock sampling in the area had revealed concentrations of $\mathrm{Pb}$ up to $1.4 \%$ and $\mathrm{Zn}$ up to $0.37 \%$ (ref. 22 ).

JPL-L2 reflectance product of AVIRIS-NG has been used for the present study ${ }^{17}$. A total of six scenes were acquired during 4-5 February 2016, covering Jahazpur and adjoining regions of Rajasthan. AVIRIS-NG instrument measures the reflected solar radiation in the spectral range $376-2500 \mathrm{~nm}$ at a spectral resolution of $5 \mathrm{~nm}$ over 425 contiguous spectral channels ${ }^{18}$. The aircraft was flown at an altitude of approximately $8 \mathrm{~km}$ providing a 
Table 1. List of spectral summary parameters used for detection and mapping of phyllosilicates and carbonates (modified after Viviano-Beck et al. ${ }^{24}$ and Pelkey et al. ${ }^{23}$ )

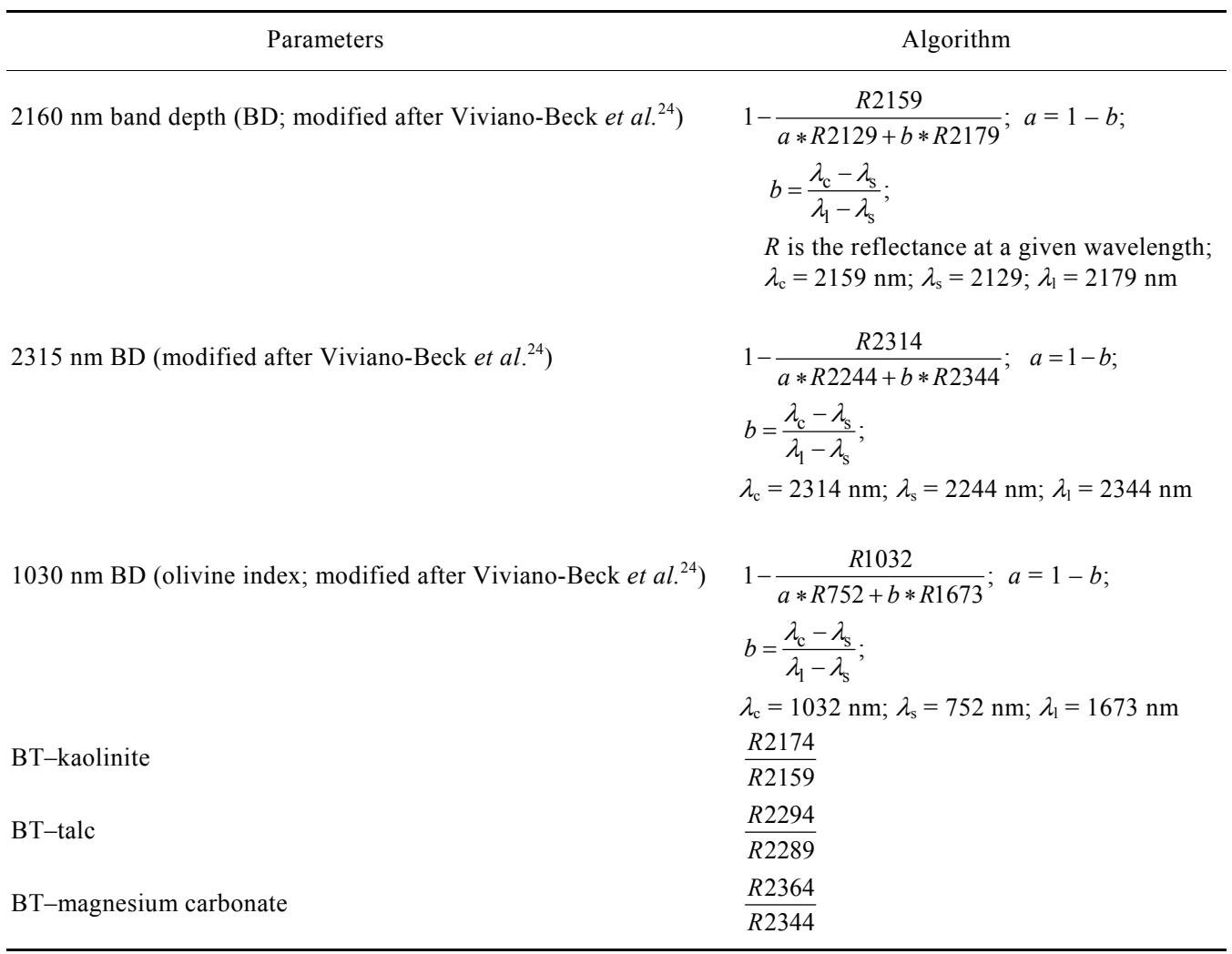

ground resolution cell of roughly $8 \mathrm{~m}$. In addition, ASD FieldSpec4 Hi-Res spectrometer has also been utilized in the spectral range $350-2500 \mathrm{~nm}$ to obtain in situ as well as lab-based reflectance spectra of rocks and soil samples collected from the field.

Methodology: The primary goal of the present study is to characterize the host rock for base metal mineralization in the Jahazpur belt using AVIRIS-NG apparent reflectance product (L2) as provided by NASA-JPL ${ }^{17}$. A total of six AVIRIS-NG scenes have been acquired and stitched to prepare a seamless mosaic of the study area using ENVI 5.5 software for the analysis of digital image data. In the present study, we have utilized the SWIR domain of AVIRIS-NG data that ranges from 1954 to $2500 \mathrm{~nm}$ for detection and mapping of host rocks for base metal mineralization and soapstone occurrences. Additionally, the near-infrared (NIR) spectra from 750 to $1700 \mathrm{~nm}$ has been utilized to identify the olivine bearing assemblages. Modified spectral summary parameters have been employed for detection and mapping of spectral endmembers of mineral species in a spatial context, originally designed for the analysis of Mars Reconnaissance Orbiter-Compact Reconnaissance Imaging Spectrometer for Mars (MRO-CRISM) data by Pelkey et al. ${ }^{23}$, followed by revised summary parameters provided by Viviano-Beck et $a l .{ }^{24}$. Table 1 and Figure 2 present formulations for the modified spectral summary parameters used in this study. Finally, false colour composites (FCCs) are obtained using the spectral summary parameters to map the dominant mineralogies present within the study area.

Results and discussion: Modified spectral summary parameters have been formulated based on the nature and shape of the diagnostic absorption features of minerals that may be present in the study area, and thus are also suitable for better discrimination of minerals having closely spaced and/or overlapping absorption features. The same has been tested on the subset of Jahazpur mosaic, where the spectral absorption features of kaolinitemontmorillonite $(2200 \mathrm{~nm})$ and dolomite-talc $(2315 \mathrm{~nm})$ exhibit overlapping absorption features. In the modified summary images, the kaolinite- and montmorillonitebearing pixels have been highlighted in a brighter tone and thresholding was done to only restrict the locations of the pure spectral endmembers. In case of kaolinite, multiple techniques were employed, such as the introduction of band tilt (BT) parameter to measure the upward tilt with respect to the short wavelength band minimum of kaolinite around $2160 \mathrm{~nm}$ (refs 25 and 26). The rationale behind choosing the pivot at $\mathrm{C} 1$ is primarily to discriminate between phyllosilicates having a single symmetric/ 

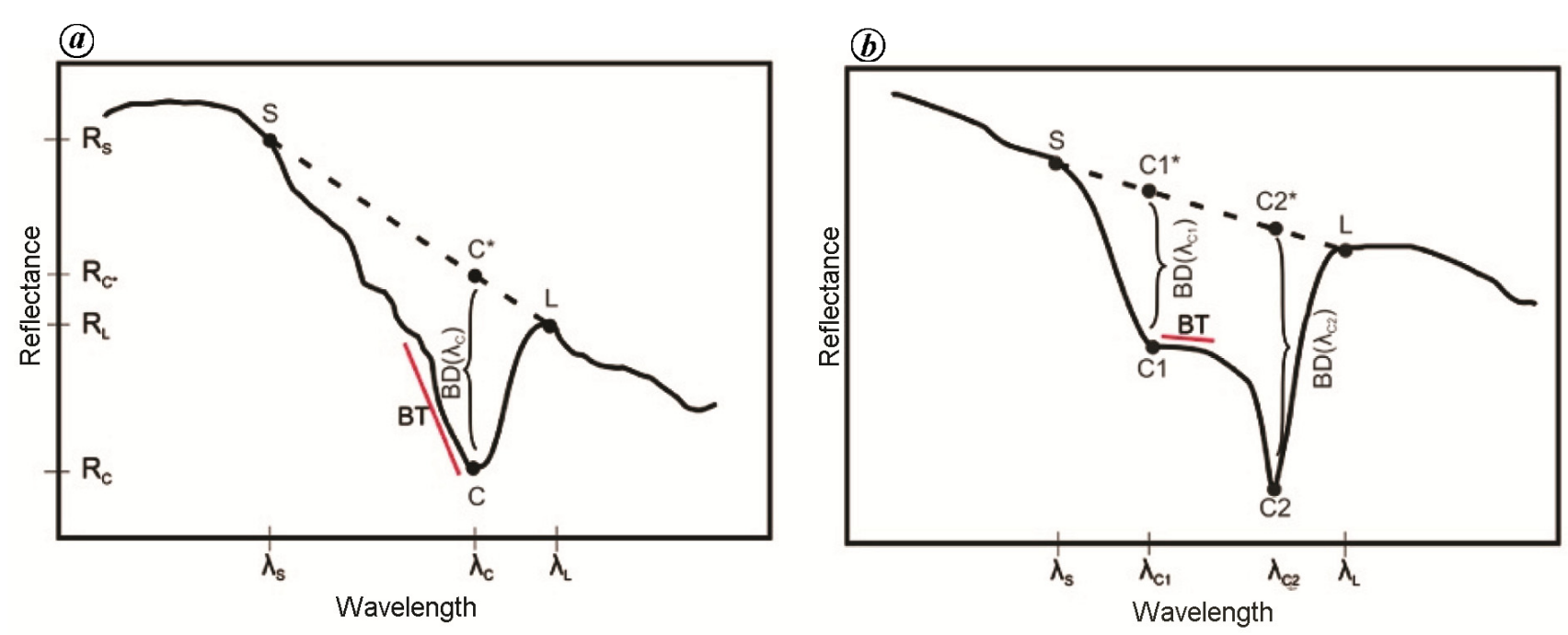

Figure 2. ( $\boldsymbol{a}, \boldsymbol{b})$ Schemata highlighting spectral band parameter formulations using ideal spectra. The dashed line indicates a continuum fit across the absorption band by which a reflectance point along the continuum is calculated. The red line indicates the nature of band tilt with respect to a pivotal point at $\mathrm{C} 1$ in $\mathrm{B}$ (modified after Viviano-Beck et al. ${ }^{24}$ ).

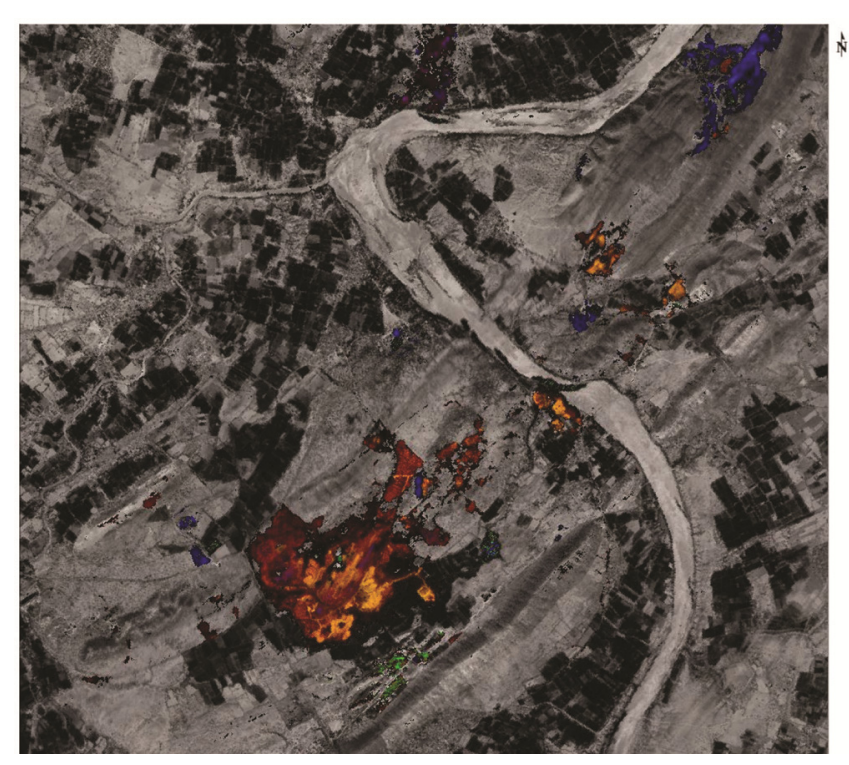

Figure 3. Spectral summary parameters highlighting the spectral endmembers of talc, magnesium carbonate, kaolinite, montmorillonite and kaosmectite (kaolinite + smectite). Magnesium carbonate-bearing host rocks appear in shades of maroon to purple, talc-bearing pixels appear in yellow, kaolinite in blue and montmorillonite in green.

asymmetric absorption feature from that of a doublet feature. Band tilt and band curvature are complementary in the sense that phyllosilicates having a single prominent absorption without any curvature would exhibit larger tilt in comparison to those having a doublet, as explained schematically in Figure 2. In addition, the short wavelength and long wavelength band depth (BD) parameters were computed separately. Whereas, in case of montmorillonite, a single $2200 \mathrm{~nm}$ BD parameter has been computed taking into account the $2129 \mathrm{~nm}$ short wavelength and $2234 \mathrm{~nm}$ long wavelength shoulders, and the asym- metry factor has also been computed. In addition, a $2349 \mathrm{~nm}$ Al-OH BD parameter and BT slope of $R 2174 / R 2159$ have been computed. Similarly, BT slope for magnesium-carbonate was computed utilizing the spectral signature of dolomite to identify the spectral region that strongly differs from that of talc spectral signature.

We have generated two separate spectral summary parameters based FCCs. In the first FCC, we have assigned red channel to $2314 \mathrm{~nm}$ BD parameter, green channel to BT-talc slope and blue channel to BTmagnesium-carbonate slope. In such a combination, dolomites and impure dolomitic marbles appear in shades of purple to maroon, whereas talc-bearing exposures appear in yellow. In the other FCC, we have assigned red channel to BD $2159 \mathrm{~nm}$ parameter, green to $2349 \mathrm{~nm}$ Al-OH BD parameter and blue channel to $2389 \mathrm{~nm}$ reflectance. In this combination, pure kaolinite-bearing pixels are highlighted in red, and kaolinite-montmorillonite mixtures in green to blue. Finally, both the FCCs have been combined to map the spatial distribution of dominating mineral species in the study region as shown in Figure 3, where the dolomites, dolomitic quartzite and impure dolomitic marbles are highlighted in shades of maroon to purple, talc in yellow, kaolinite in blue and montmorillonite in green.

In another FCC combination (Figure 4), we have assigned modified BD-magnesium-carbonate as red, modified olivine index as green and BD-2389 nm talc parameter as blue on the Jahazpur mosaic obtained by stitching six AVIRIS-NG side-lapped scenes. In this combination, all the impure dolomitic marbles having forsterite appear in yellow, talc-bearing exposures appear in magenta to pink, and dolomites appear in red to maroon to orange. In this FCC, kaolinite appears as 
bluish-green to greenish-blue, and montmorillonite as dark green. The modified CRISM spectral summary products along with the BT parameter originally designed for analysing the Clementine UV/VIS ${ }^{26}$ and Chandrayaan-1 HySI data ${ }^{25}$ are found to be extremely effective in not only discriminating among the mineral species, but also in differentiating minerals having overlapping absorption features.

Conclusions: CRISM summary products as developed by Pelkey et $a l .{ }^{23}$ and subsequently modified/revised by Viviano-Beck et $a .^{24}$ have been implemented on AVIRIS-NG data covering parts of Jahazpur mineralized belt. Fe-Mg-bearing major rock-forming silicates can also be mapped efficiently based on the spectral parameters as presented in this study, whereby the occurrence of forsterite has been detected in the impure marble exposure at Jahazpur. Application of spectral summary parameters, thus helps in the identification of mineral endmembers spatially within a hyperspectral scene without using spectral and spatial data dimensionality reduction techniques that are often computationally intensive procedures.

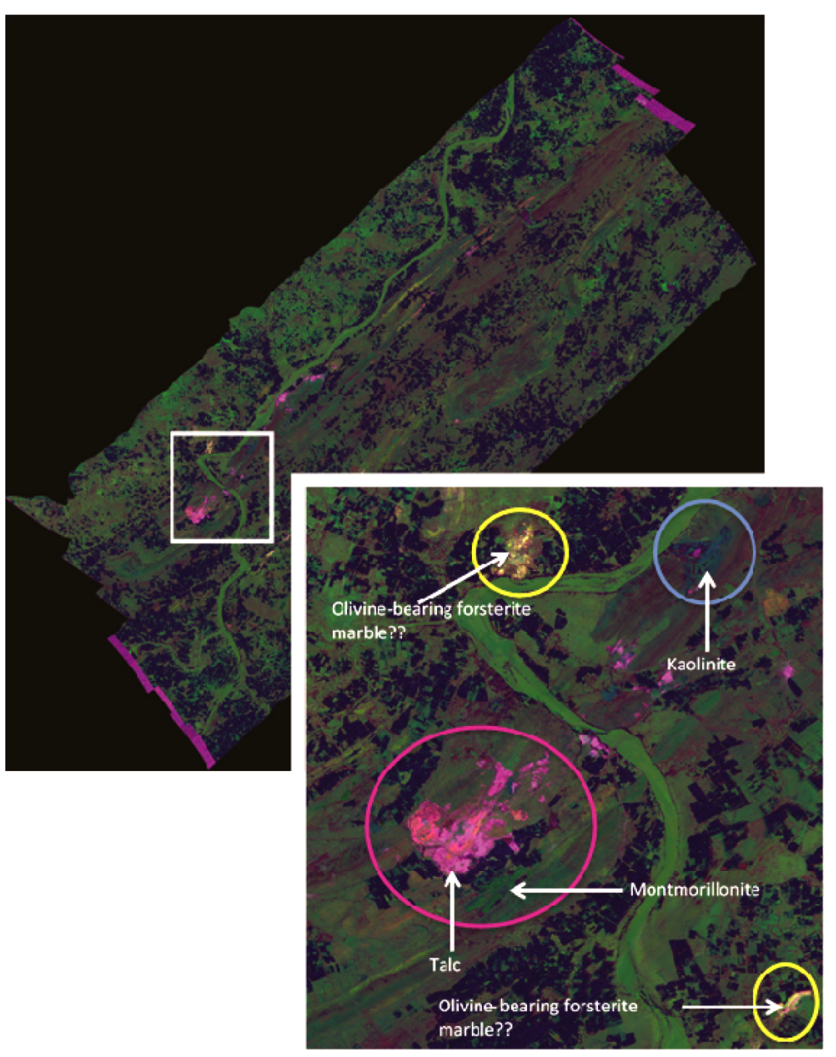

Figure 4. False colour composite (FCC) obtained by assigning red channel to $2310 \mathrm{~nm}$ magnesium carbonate band depth (BD) parameter; green to $1030 \mathrm{~nm}$ olivine (O1) BD and blue to $2200 \mathrm{~nm}$ clay BD parameter. In this FCC, combined olivine- and carbonate-bearing pixels appear in yellow, magnesium carbonate in red to orange to maroon, soap stones (talc) in magenta, kaolinite in bluish-green and montmorillonite in dark green.

\section{Ambaji}

Geology of the study area: The rocks of Ambaji-Deri region belong to the lower part of Ajabgarh series, which forms part of Delhi Supergroup of rocks. Calc-silicate and impure marbles are the oldest rocks of Delhi Supergroup exposed in the region and belong to Todgarh formation of Kumbalgarh Group. General trend of metamorphosed sediments is NNW-SSE and they dip vertically to sub-vertically. The granitic rocks of the area are considered as intrusive into the Ajabgarh Group and are correlated with Erinpura granite ${ }^{27}$. The basic rocks intruded into Ajabgarh phyllite as sill-like intrusives and later metamorphosed to amphibolites ${ }^{28}$.

Ambaji-Deri region is well known for the occurrence of base metals lead, zinc and copper. Mineralization occurs in metamorphosed magnesian and calc-magnesian rocks ${ }^{29}$. Chloritic hornfels and diopside marbles are the main host rocks for sulphide mineralization, while some mineralization is also noticed in biotite-quartz schist ${ }^{29}$. The ore body occurs in the form of lenses and tabular bodies, and shows concordant relationship with primary stratification and schistosity of the host rock. In the present study, we map the host rocks of base metal mineralization in parts of Ambaji. Integrated band depth (IBD) technique has been employed to map the carbonate and clay-rich zones ${ }^{30}$. We also differentiate between magnesian and calcium rich lithologies. The results show potential of imaging spectroscopy for mapping of surficial mineral composition.

Mapping of deepest absorption feature in 2.0-2.5 $\mu \mathrm{m}$ spectral range: Several minerals such as phyllosilicate, carbonates and sulphates have diagnostic absorption feature in the SWIR region and are called infrared-active. Therefore, mapping of wavelength position of deepest absorption feature and its depth is important for exploratory analysis of surficial composition and broad identification of mineral groups.

To map the wavelength of deepest absorption feature, continuum was first removed from the spectra to highlight diagnostic absorption features. Continuum was removed for each pixel by calculation of convex hull of spectra and its subsequent division, as described in Clark and Roush ${ }^{31}$. To calculate the wavelength position of deepest absorption feature, methodology described in Rodger et al. ${ }^{32}$ was used.

Integrated band depth mapping: IBD is a mineral indicator parameter developed by Mustard et al. ${ }^{30}$. It captures the fundamental mineralogical variations of the surface by summing the BD of diagnostic absorption feature. We have used IBD at 2.30 and $2.20 \mu \mathrm{m}$ as an indicator of carbonates and clays respectively. The following equations were used to derive IBD for carbonate and clay mapping. 
For carbonates:

$$
\sum_{n=0}^{44} 1-\frac{R(2189-5 n)}{R_{\mathrm{c}}(2189+5 n)}
$$

For clays:

$$
\sum_{n=0}^{21} 1-\frac{R(2134-5 n)}{R_{\mathrm{c}}(2134+5 n)}
$$

Here $R$ refers to reflectance at a given wavelength. $R_{\mathrm{c}}$ is continuum reflectance and is represented as a straight line across the absorption band. Width of the diagnostic absorption feature is determined by its initial and final wavelengths. In case of calcite, it is determined to be 2.18 (left shoulder) and $2.40 \mu \mathrm{m}$ (right shoulder). Number 5 in eqs (1) and (2) represents spectral resolution of the sensor and $n$ is the number of channels/spectral bands over which integration is performed. One of the major advantages of IBD is that it uses summation of band depths over wavelengths of diagnostic absorption feature and enhances the signal-to-noise ratio, thereby reducing the uncertainty involved in mapping of targeted minerals.

Mapping of deepest absorption feature in SWIR: Figure 5 shows a map of deepest absorption feature in SWIR region for parts of Ambaji. The most dominant absorption feature in the image is noticed near $2.31-2.35 \mu \mathrm{m}$. The absorption in wavelength range $2.31-2.35 \mu \mathrm{m}$ occurs due to the presence of rock-forming minerals such as carbonates, tremolites and epidotes. At several locations, absorption near $2.20 \mu \mathrm{m}$ is also observed. Clay and mica are common minerals responsible for absorption near $2.20 \mu \mathrm{m}$. Detailed spectral analysis of regions showing absorption at SWIR wavelength in Figure 5 was carried out to understand the spectral characteristics of these minerals.

Spectral analysis: Based on above analysis of wavelength position of deepest absorption features, detailed analysis of image spectra at locations showing absorption near $2.20 \mu \mathrm{m}$ and $2.32 \mu \mathrm{m}$ was carried out. During the field campaign, rock samples corresponding to various lithologies exposed in the region were collected for laboratory reflectance spectroscopic studies. Locations of samples collected during field campaign are marked in Figure 5. At location S1 (Figure 5), exposures of carbonates are visible; this location is an active marble quarry north of Ambaji on the way to Koteshwar Temple. Figure 6 shows photographs of some of the lithologies encountered in the field. Figure 7 displays field spectra of marble collected from mine (S1 in Figure 5), showing absorption features at $1,1.4,1.9,2.31$ and $2.39 \mu \mathrm{m}$. Absorption feature occurring at $1 \mu \mathrm{m}$ is possibly due to presence of iron, while those occurring at $1.4 \mu \mathrm{m}$ and
$1.9 \mu \mathrm{m}$ are attributed to the presence of hydroxyl ions and water in the crystal structure. A very strong absorption feature is observed at $2.314 \mu \mathrm{m}$. Based on wavelength of absorption feature $(2.314 \mu \mathrm{m})$ and spectral shape, the mineral is identified as dolomite. Carbonates show this absorption feature due to vibrational process in $\left(\mathrm{CO}_{3}\right)^{2-}$ (refs 33 and 34). Location S2 (Figure 5) shows exposures of fractured pink granites (Figure 6). Granitic rocks are rich in quartz and plagioclase feldspar. Pure quartz is featureless in the $0.38-2.5 \mu \mathrm{m}$ spectral range. Plagioclase feldspar exhibits absorption features in the wavelength range $1.1-1.3 \mu \mathrm{m}$, which is attributed to electronic transitions in $\mathrm{Fe}^{2+}$ (ref. 35). Substitution of iron in plagioclase crystals occurs at aluminium and calcium sites ${ }^{36}$. The spectra of pink granite (Figure 7) show absorption features near $0.86,1.4,1.9$ and $2.20 \mu \mathrm{m}$. It can be noticed that diagnostic absorption feature near $1.25 \mu \mathrm{m}$ is missing in the spectra. It may be possible that iron content of feldspar crystal is very low to cause any appreciable absorption near $1.25 \mu \mathrm{m}$. The absorption feature near $0.86 \mu \mathrm{m}$ is due to the presence of ferric iron $\left(\mathrm{Fe}^{3+}\right)$, while those at $1.4 \mu \mathrm{m}$ and $1.9 \mu \mathrm{m}$ are due to the presence of hydroxyl ions and water in the crystal structure. Doublet at $2.20 \mu \mathrm{m}$ occurs due to metal-OH (aluminium-OH) bonding. Based on the shape of diagnostic absorption feature near $2.20 \mu \mathrm{m}$, the mineral is identified as kaolinite/ halloysite. Kaolinite and halloysite are aluminium-rich clay and have identical chemical composition. Halloysite differs from kaolinite in that the former contains structural $\mathrm{H}_{2} \mathrm{O}$ that is well manifested by a strong and relatively broad absorption near $1.9 \mu \mathrm{m}$ compared to that in the lat$\operatorname{ter}^{37}$. In AVIRIS-NG data, as the signals near $1.4 \mu \mathrm{m}$ and

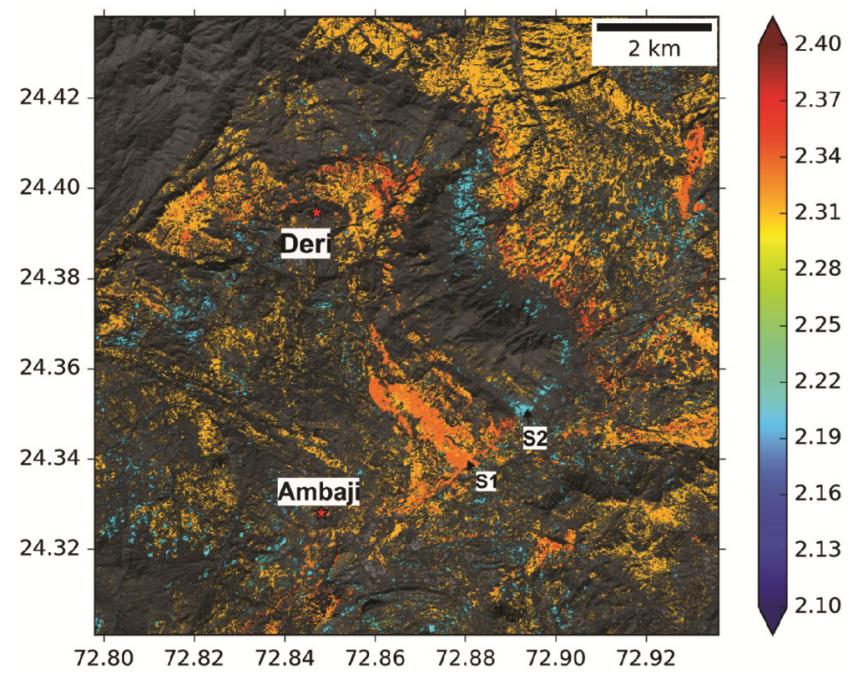

Figure 5. Wavelength of deepest absorption feature in Ambaji region overlaid on LISS-IV image. Absorption due to calcite at $2.34 \mu \mathrm{m}$ is shown in reddish colour, $2.31 \mu \mathrm{m}$ due to dolomite appears in yellowish colour. Absorption at wavelength $2.20 \mu \mathrm{m}$ due to clay minerals is seen in cyan colour. S1 and S2 represent the sampling locations of marble and pink granite respectively. Pixels containing vegetation are masked. 

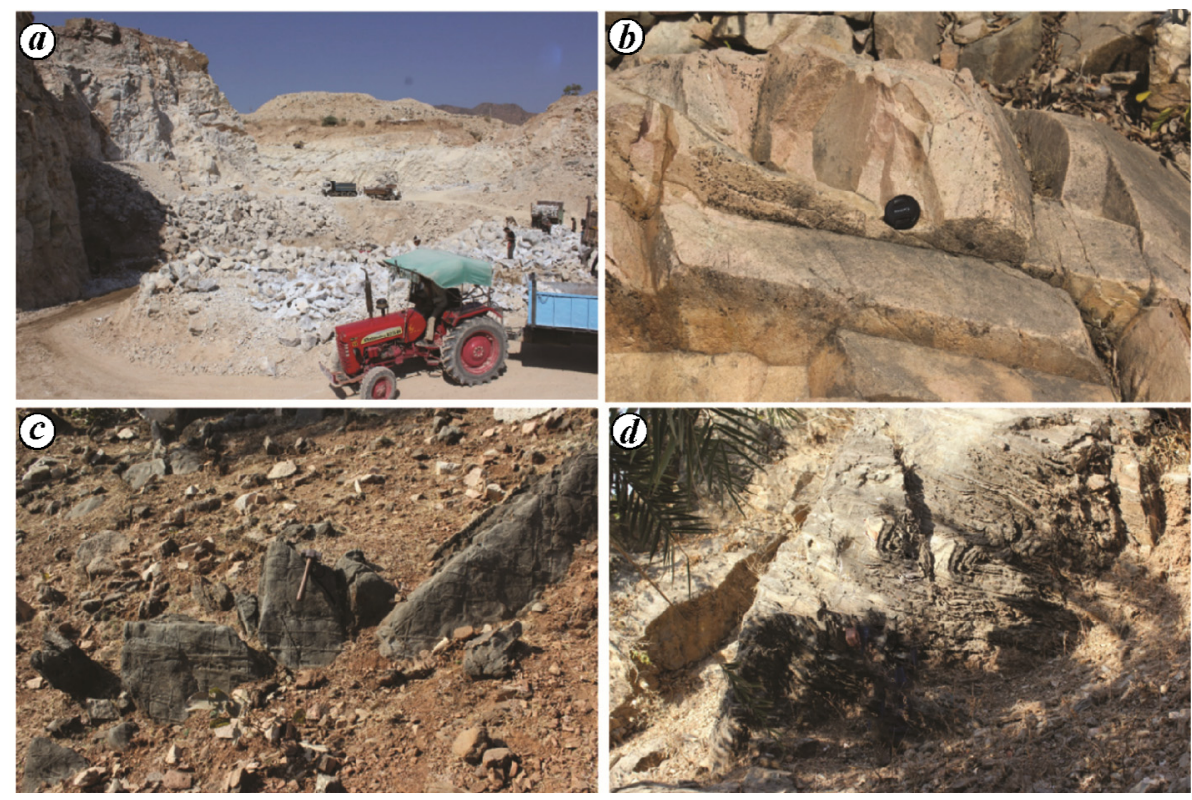

Figure 6. Field photographs showing various lithologies. a, Marble quarry (marked as S1 in Figure 5) north of Ambaji; $\boldsymbol{b}$, Pink granite (marked as S2 in Figure 5) near Koteshwar; $\boldsymbol{c}$, Dolomitic marble near Deri; $\boldsymbol{d}$, Complex folding in calc-silicate.

$1.9 \mu \mathrm{m}$ are completely obscured by atmospheric constituents, it would be difficult to discriminate kaolinite from halloysite based solely on the nature of the $2.2 \mu \mathrm{m}$ doublet feature.

Use of integrated band depth for carbonate and clay mapping: IBD calculated over certain chosen wavelength ranges keeping in view diagnostic absorption feature of the minerals is an important parameter for mapping and understanding the distribution of a particular mineral group. In this study, we have used IBD values at $2.30 \mu \mathrm{m}$ and $2.20 \mu \mathrm{m}$ as indicators of carbonate and clay mineralogy respectively.

Strength of an absorption feature is dependent upon grain size and abundance ${ }^{37}$. If we assume grain size to be constant, then depth of the absorption feature is directly proportional to the abundance of the material. However, several factors such as mineral coating complicate the abundance and band depth relationship. Nevertheless, determining a suitable threshold to mask the low IBD values may be useful to suppress the ambiguous pixels and map the mineral group of interest. We chose the threshold values using hit and trial method. To check the accuracy of the threshold, we examined the reflectance spectra of pixels having lowest IBD values. If the spectral characteristics agreed with the mineral group mapped, we fixed the threshold for that particular group. In this way, threshold for carbonate was found to be 0.5 and for clay as 0.2 . It is to be noted that this threshold may vary with region and quality of spectral data.

Figure 8 shows IBD for $2.30 \mu \mathrm{m}$ absorption feature. High values of IBD indicate presence of carbonate as confirmed by analysis of the spectra. It is clearly noted that the region marked as rectangle 1 in the figure has very high band depth $(>3)$ values and is an active marble quarry north of Ambaji, as verified in the field. Low values of IBD are observed in the region where carbonates have developed black-coloured coating on their surface. The coating reduces the overall albedo, which may reduce the band depth. Regions of low IBD $(<0.5)$ have been masked, as low IBD values indicate absence of carbonates.

Figure 9 shows the distribution of IBD for $2.20 \mu \mathrm{m}$. It can be noted that areas with high IBD values $(0.2-1)$ are representative of clay minerals, as they exhibit strong absorption feature near $2.20 \mu \mathrm{m}$. Analysis of reflectance spectra over regions of high IBD confirms the presence of kaolinite/halloysite. At the locations (rectangle 1 in Figure 8) where IBD values for $2.20 \mu \mathrm{m}$ are relatively higher $(\sim 0.9)$, show exposures of pink granite as seen in the field (Figure 6). During field validation it was noted that regions with high IBD values at $2.20 \mu \mathrm{m}$ correlate well with granitic rock exposures. This suggests that the absorption feature at $2.20 \mu \mathrm{m}$ may be used to map granite outcrops in Ambaji.

As mineralization in Ambaji and Deri mostly occurs in metamorphosed magnesian and calc-magnesian rocks, mapping of exposures of calc-silicate rock is important for detailed field-based studies on the extension of currently known base metal mineralized zone. Further, these rocks are also a source of marble; and spatial extent of carbonate rocks may be useful for marble exploration activities. Clay minerals often act as important indicators of hydrothermal alterations. Zones of intense alteration are 

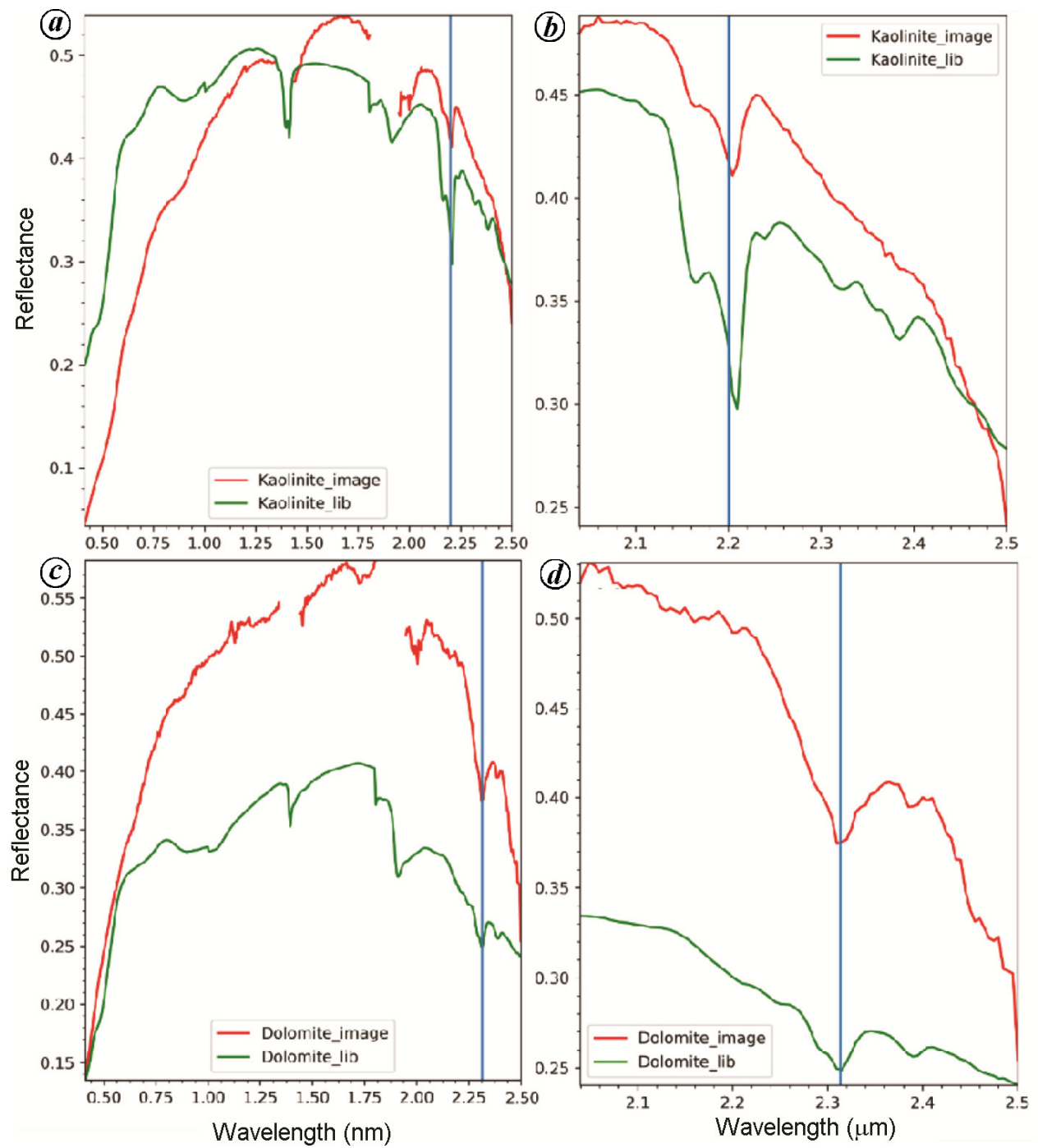

Figure 7. $\boldsymbol{a}$, Reflectance spectra of pink granite (sample collected from S2) and spectra collected from image in the wavelength range $0.4-2.5 \mu \mathrm{m} . \boldsymbol{b}$, The spectra show prominent absorption features at 1.4, 1.9 and $2.2 \mu \mathrm{m}$. Diagnostic absorption feature located in the SWIR region. $c$, Reflectance spectra of marble (sample collected from S1) and spectra collected from image in the wavelength range $0.4-2.5 \mu \mathrm{m}$. $\boldsymbol{d}$, The spectra show prominent absorption features at 1.4, 1.9 and $2.32 \mu \mathrm{m}$. Diagnostic absorption feature located in the SWIR region. Laboratory and image-based spectra show good match of absorption wavelength and spectral shape.

of interest in mineral exploration projects as they form the most prospective sites for base and precious metal mineralization. Clay-rich zones mapped in the present study may be further examined in detail to assess their potential in locating mineralized zones.

Conclusions: Mapping of the deepest absorption feature in the wavelength range $2.0-2.5 \mu \mathrm{m}$ where most of the minerals have their diagnostic absorption features is useful for exploratory analysis of the data. It gives an overview of surface mineral diversity/mineral group likely to be present in the study area and helps in identification. Inter-comparison of image, library and laboratory-based spectra reveals that diagnostic absorption features present in the SWIR region are in good agreement. However, presence of strong atmospheric water absorption at
$1.4 \mu \mathrm{m}$ and $1.9 \mu \mathrm{m}$ corrupts the image, thereby hindering inter-comparison.

It is evident that IBD can map the spatial distribution of particular groups of minerals such as clays and carbonates. IBD is less sensitive to noise present in a single channel, as it is the summation of all the channels covering diagnostic absorption features. Shift in absorption wavelength due to subtle mineralogical variations of carbonates is useful for discrimination between calcite and dolomite, and helps in mapping magnesian and calc-magnesian rocks.

\section{Sittampundi layered complex and Wajrakarur Kimberlite field}

Potential use of AVIRIS-NG data for mapping ultramafic rocks (host rocks of chromite) has been discussed in the 
literature with reference to mapping of the exposures of Ronda peridotite massif ${ }^{38}$. ASTER data have also been used for mapping ultramafites and chromites in different parts of the world ${ }^{39,40}$. In the present study, we analyse the potential of ASTER and AVIRIS-NG data for mapping patchy exposures of chromitite. Record on the comparative analysis of spaceborne ASTER and AVIRIS-NG data (collected from airborne platform and having considerable high spatial resolution of $4 \mathrm{~m}$ to $6 \mathrm{~m}$ ) in mapping such exposures is meagre in the literature, especially for countries like India where ultramafic rocks are easily weathered. In this study, we have analysed the potential of AVIRIS-NG data in delineating surface signatures or surface exposures of chromitite and kimberlite in SLC and WKF respectively (Figure 10).

Methodology: In our effort to map the chromitite exposures, we have used AVIRIS-NG Level 1B data ('georectified at sensor radiance') for mapping chromitite. We have calibrated the data to 'scaled-reflectance' based on MODTRAN-4 atmospheric calibration model used in 'Fast Line of sight Atmospheric Analysis of Spectral Hypercube' (FLAASH) module in ENVI software. This Atmospheric Correction Algorithms (ACAs) has been widely used in applications of remotely sensed hyperspectral data to correct for the effects of atmospheric propagation on measurements acquired by air and spaceborne systems, to convert the radiance data to reflectance $^{41}$. It is essential for reflectance spectroscopy-based target detection using different spectral mapping algorithms. Concurrently, ASTER data ('georectified at sensor radiance') are also calibrated to scaled reflectance image using FLAASH. Scaled reflectance data of AVIRIS-NG and ASTER are subjected to spectral enhancement and spectral mapping. Ground magnetic data are collected from SLC using precision magnetometer with grid spacing of 500-700 m, to supplement and validate the results of spectral mapping. Grid spacing is variable to account for the presence of highly magnetic bodies (electric wire heads, concealed pipe, etc.) on ground. Ground magnetic data collected for the area are corrected for diurnal drift variation (due to solar activity). Consequently, International Geomagnetic Reference Field 2016 (IGRF 2016) values are subtracted from the observed magnetic field values for each data point ${ }^{42,43}$. Ground magnetic data also would be useful to delineate the concealed mafic units. We have taken magnetic data approximately $3-5 \mathrm{~km}$ beyond the extent of SLC to estimate the precise magnetic anomaly for the edges of the complex.

Sittampundi layered complex: SLC is a metamorphosed magmatic anorthosite-dominant layered complex occurring within orthogneiss and amphibolites ${ }^{44,45}$. Pyroxenite exposures and other metaultramafites are exposed in the eastern part of the study area. Patchy exposures of chro- mitites are reported in the eastern part of SLC. These are associated with chromitite dumps excavated out using exploratory trenches. We delineate these exposures based on sub-pixel mapping method, as exposures of chromitite are not resolvable in the resolutions of AVIRIS-NG data. In this regard, adaptive coherence estimator (ACE)

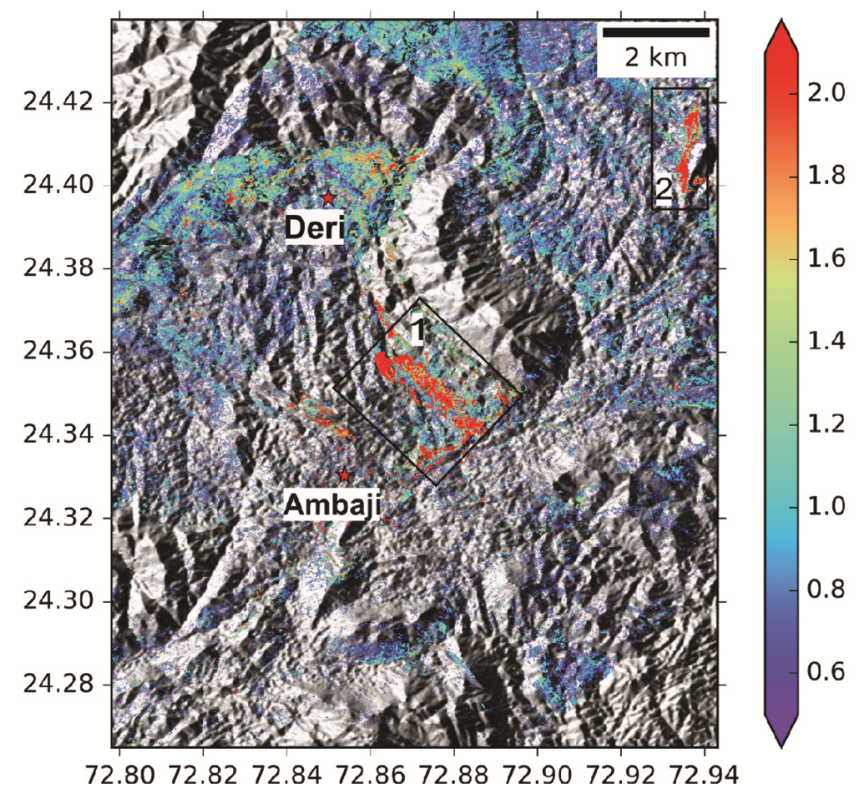

Figure 8. Integrated band depth (IBD) at $2.30 \mu \mathrm{m}$ showing distribution of carbonates in parts of Ambaji region overlaid on Digital Elevation Model (DEM). Marble quarries located north of Ambaji (marked as rectangle \#1), are seen in reddish tone. A marble-rich zone marked in rectangle \#2 is also detected on the IBD image.

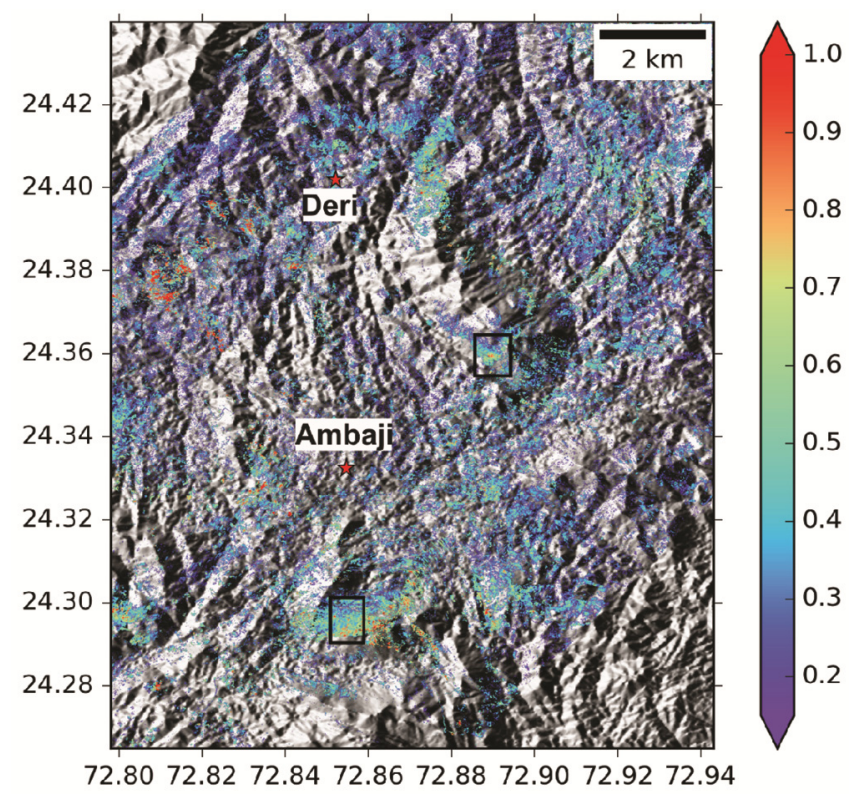

Figure 9. IBD at $2.20 \mu \mathrm{m}$ showing distribution of clay minerals in parts of Ambaji region overlaid on DEM. The clay minerals are generally associated with granites in the region. Rectangles shows location where presence of granite has been verified in the field. 


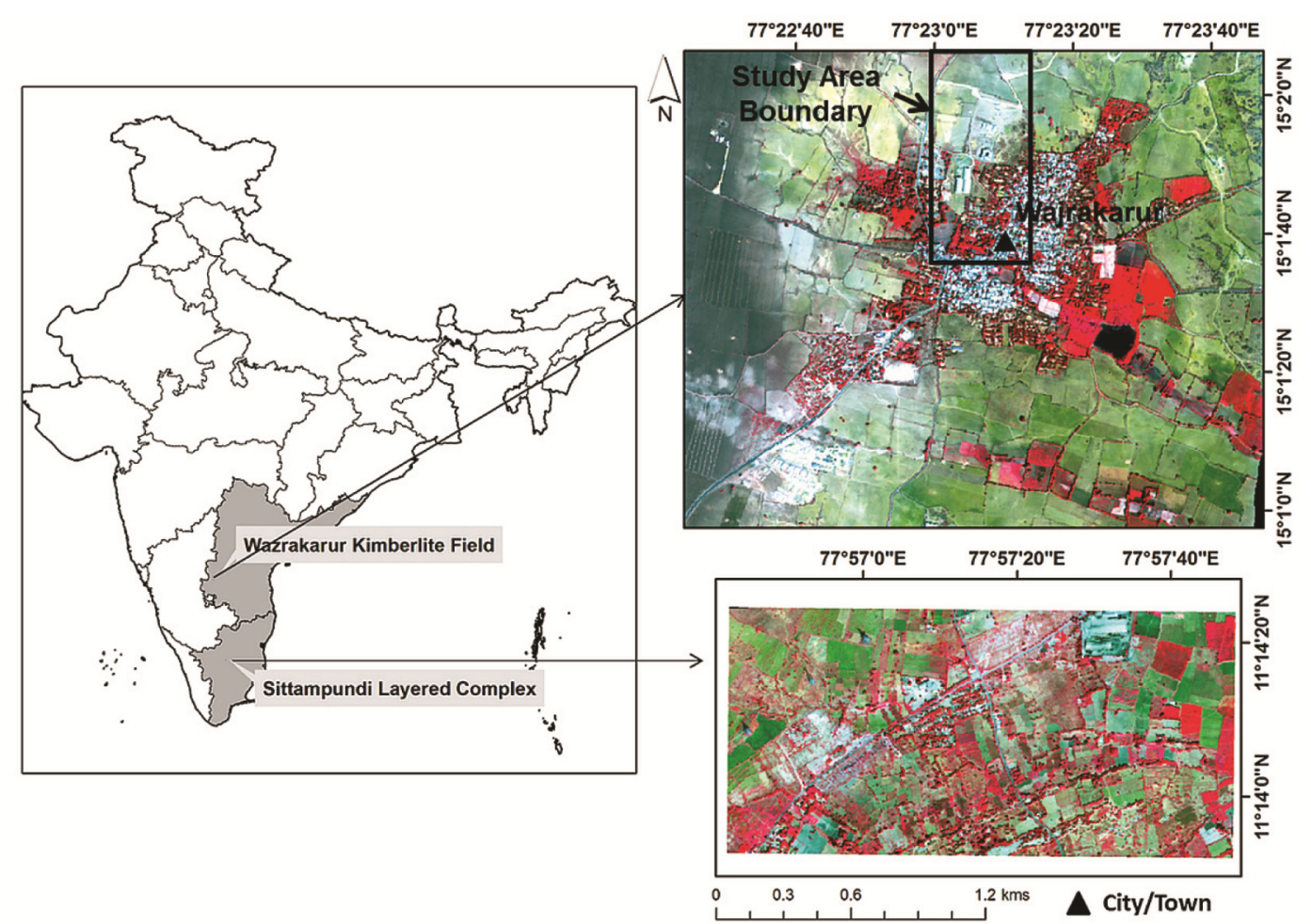

Figure 10. Study areas at Wajrakarur Kimberlite Field (WKF), Andhra Pradesh and Sittampundi Layered Complex (SLC), Tamil Nadu.
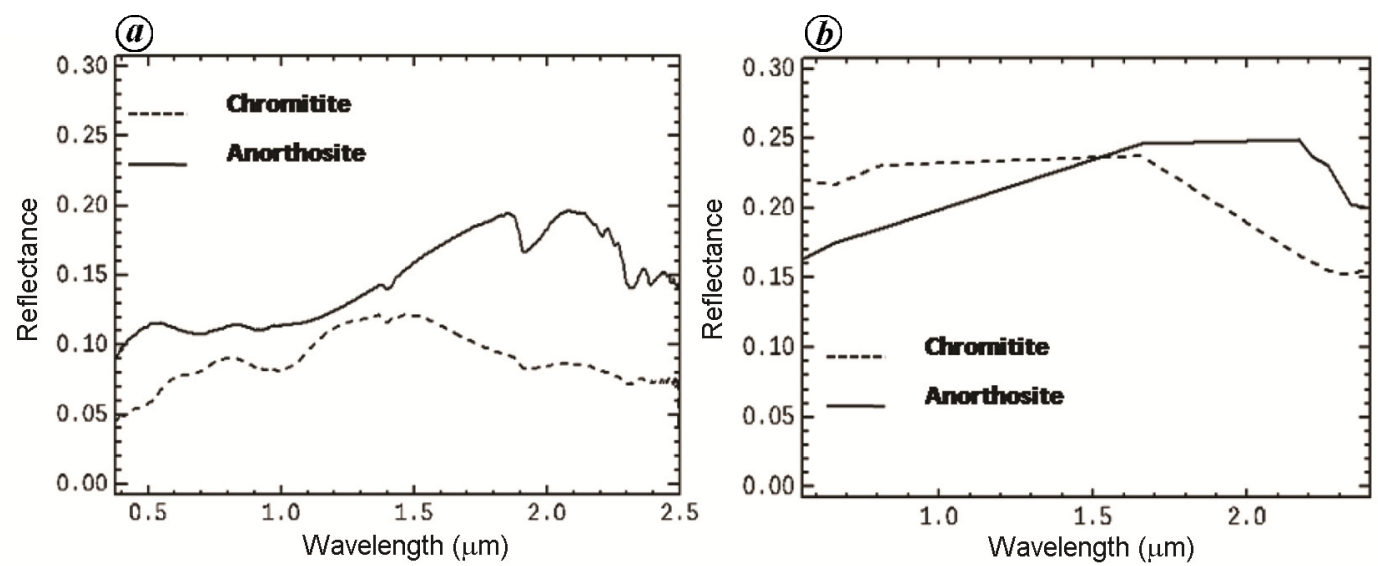

Figure 11. $a$, AVIRIS-NG resampled laboratory spectral profiles of chromitite and dominant rocks of layered complex (anorthosite). $\boldsymbol{b}$, ASTER resampled laboratory spectral profiles of chromitite and anorthosite.

method is applied to delineate the chromitite exposures and associated chromitite dumps at the eastern part of the study area concurrently on AVIRIS-NG and ASTER data. ACE is a partial sub-pixel spectral mapping method in which each pixel spectrum is decomposed based on the target spectra to identify targets within the background ${ }^{46}$. Background spectrum is estimated using general likelihood ratio. We have observed that spectral contrast of chromitite and anorthosite is conspicuous for AVIRISNG resampled laboratory reflectance spectra and ASTER (Figure $11 a$ and $b$ ). While processing AVIRIS-NG and
ASTER data, the respective sensor resampled laboratory spectra of chromitite are used as endmembers to delineate chromitite in AVIRIS-NG and ASTER data respectively. AVIRIS-NG data are found to be superior in delineating chromitite (Figure $12 a$ and $b$ ). All the surface exposures (marked as 1 and 2 in Figure $12 a$ and $b$ ) and associated chromitite dump (marked as 3 in Figure $12 a$ and $b$ ) are delineated in the CEM (constrained energy minimization) classified image (Figure $12 a$ and $b$ ). Most of these exposures are associated with high magnetic anomaly. We also have found some concealed anomaly in the northeastern 

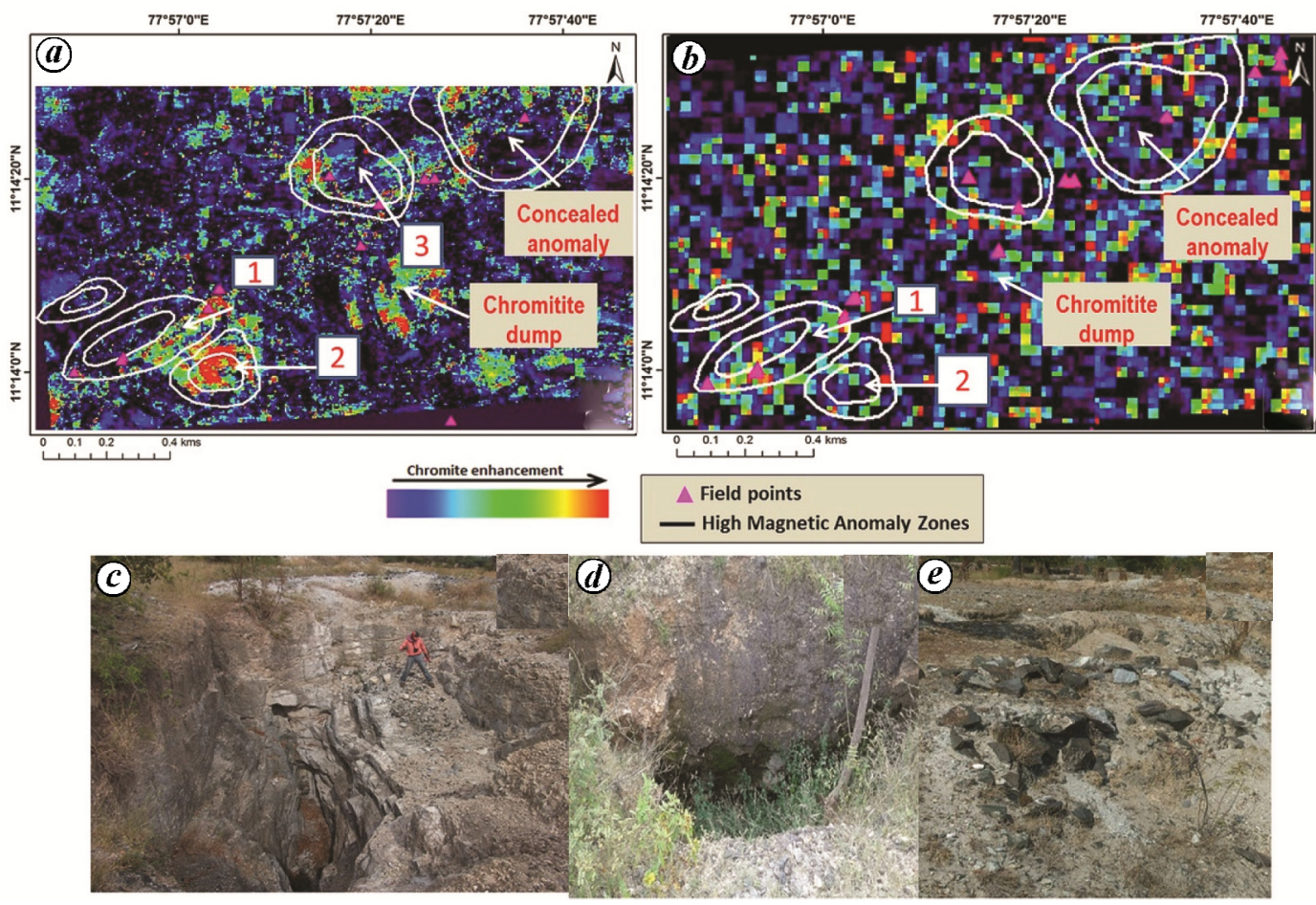

Figure 12. $\boldsymbol{a}$, Spectral map of chromitite derived from processing AVIRIS data at the eastern part of the study area in which chromitite exposures are detectable $(1,2)$ using adaptive coherence estimator (ACE) method. High magnetic contours were draped on the spectral map of chromitite. $\boldsymbol{b}$, ACE abundance map of chromitite derived from processing ASTER data. None of surface exposures of chromitite $(1$ and 2$)$ and chromitite dump is delineated in ASTER map of chromitite. $\boldsymbol{c}$, Surface exposures (1) of chromitite. $\boldsymbol{d}$, Surface exposure of chromitite along exploratory trench (2). $\boldsymbol{e}$, Surface dump of rocks rich in chromitite excavated during exploration activity.

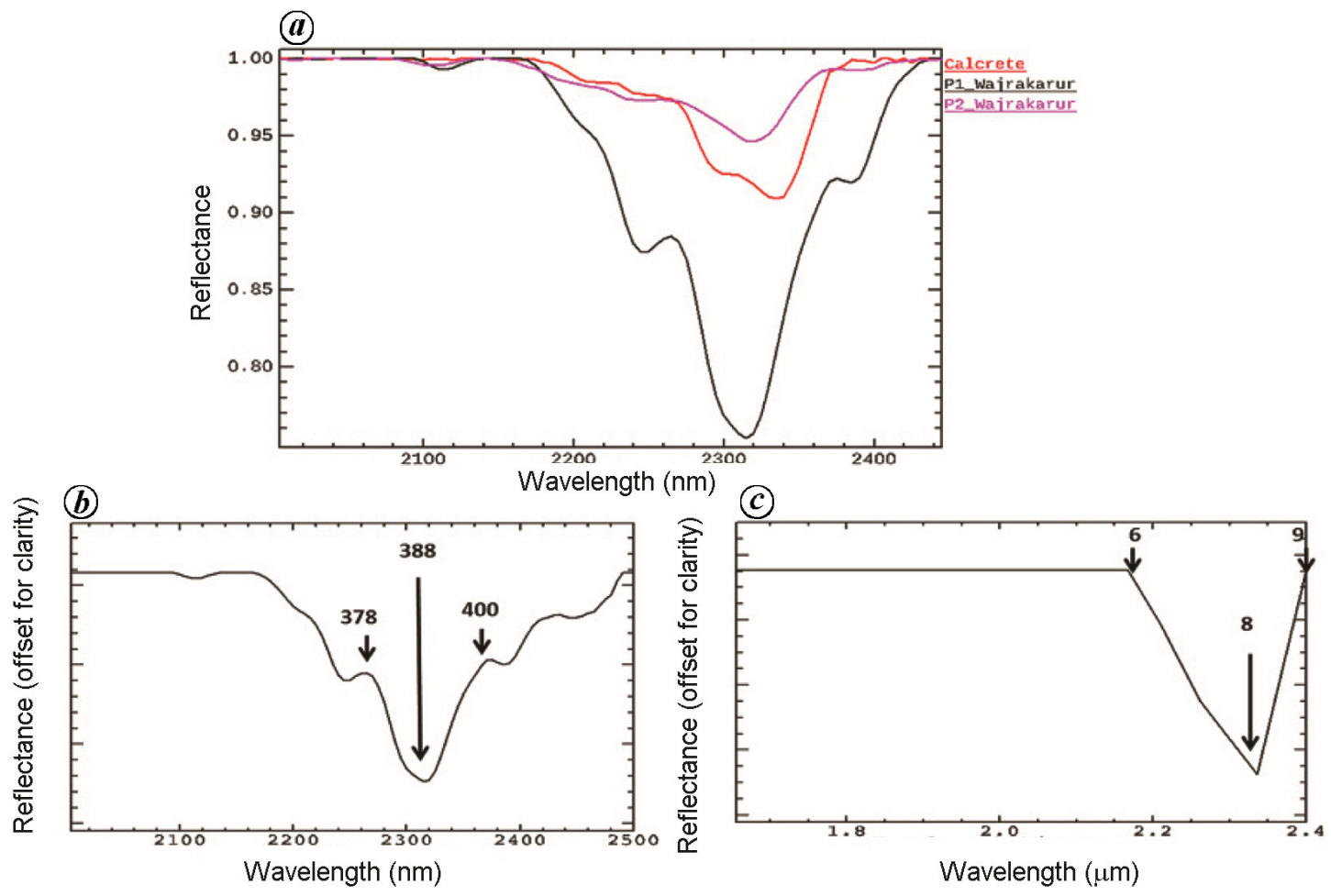

Figure 13. $\boldsymbol{a}$, SWIR domain spectral profile of calcrete and kimberlite. $\boldsymbol{b}$, AVIRIS-NG resampled spectral profiles of a mixture of kimberlite and calcretes. $\boldsymbol{c}$, ASTER resampled spectral profiles of a mixture of kimberlite and calcretes (assuming that calcretes and kimberlite are mixed in equal proportion). Bands used for deriving relative band depth image are shown. 


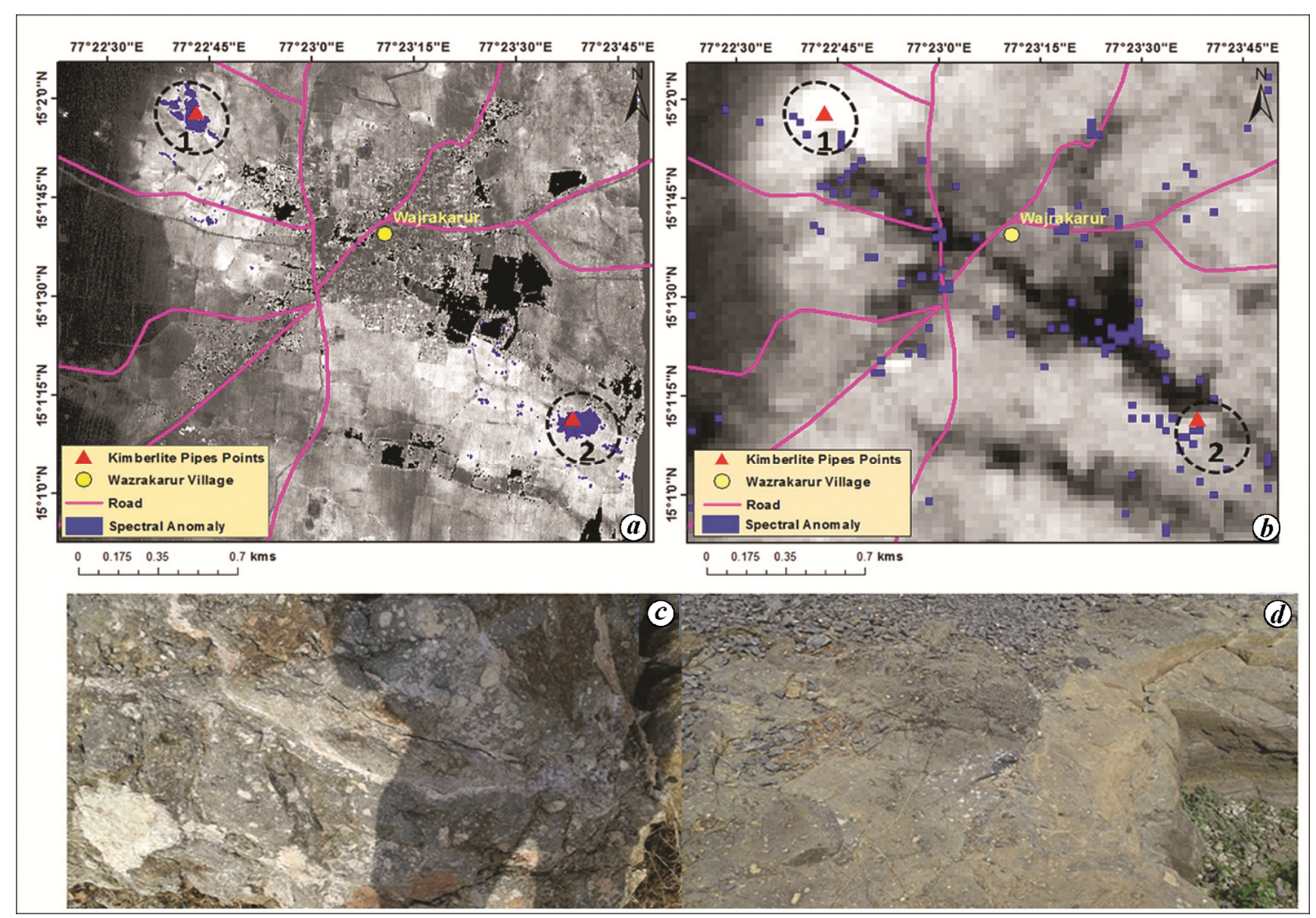

Figure 14. $\boldsymbol{a}$, Thresholded AVIRIS-NG derived relative band depth image using bands 378 and 400 of AVIRIS-NG sensor as shoulder and band 388 as absorption minima. $\boldsymbol{b}$, Thresholded ASTER-derived relative band depth using bands 6 and 9 of ASTER sensor as shoulder and band 8 as absorption minima. $\boldsymbol{c}$, Field exposure of kimberlite pipe 1 (labelled as ' 1 ' in $(\boldsymbol{a})$ ). $\boldsymbol{d}$, Field exposure of kimberlite pipe 2 (labelled as ' 1 ' in $(\boldsymbol{a})$ ).

part of the study area. In these places, high magnetic anomaly contours are present, but no significant surface exposures of chromitite pixels are identified. These areas are promising sites for concealed chromitite body if magnetic anomalies are supplemented with other geophysical data like gravity anomaly.

Wajrakarur Kimberlite field: We also delineate the kimberlite exposures in Wajrakarur area based on processing of Level-2 AVIRIS-NG data supplied by JPL after implementing atmospheric correction on the at-sensor radiance data. WKF is known for the reported occurrences of kimberlite, and these pipes have very small and patchy exposures associated with calcrete-rich zones on the surface ${ }^{47,48}$. Spectral characters of different pipes of this kimberlite field are well studied ${ }^{48}$. Spectral signatures of kimberlite and calcretes were analysed in the SWIR domain to delineate kimberlite in AVIRIS-NG and ASTER data (Figure $13 a-c$ ). Both kimberlite (serpentine-rich) and associated calcrete have absorption feature around $2.3 \mu \mathrm{m}$ (Figure $13 a-c$ ). The serpentinized kimberlite and associated calcrete occupy few pixels in
AVIRIS-NG data. Therefore, we have proposed relative band depth (RBD) image using absorption feature of mean spectra derived based on the assumption that equal proportion of each pixel is occupied by serpentine rich kimberlite and calcrete. A suitable threshold was applied on RBD to delineate kimberlite-bearing pixels in AVIRIS-NG data and results are validated in the field (Figure 14a). ASTER data could not delineate kimberlite as segregated, homogeneously distributed pixels (Figure $14 b)$. Delineated kimberlite pixels were validated in the field (Figure $14 c$ and $d$ ).

Thus, it can be concluded that AVIRIS-NG data collected from airborne platform with high spectral and spatial resolution are suitable to delineate ultramafites using their spectral contrast with the associated background rocks. It is essential to integrate spectral anomaly map with other geological and geophysical data to prove the exploration significance of these anomalies.

1. Goetz, A. F. H., Three decades of hyperspectral remote sensing of the Earth: a personal view. Remote Sensing Environ., doi:10,1016/j.res.2007.12.014. 
2. Goetz A. F., Vane G., Solomon J. E. and Rock B. N., Imaging spectrometry for Earth remote sensing. Science, 1985, 228, 4704, 1147-1153.

3. Clark, R. N., King, T. V. V., Klejwa, M. and Swayze, G. A., High spectral resolution reflectance spectroscopy of minerals. JGR, 1990, 95, 12653-12680.

4. Pieters, C. M. et al., Character and spatial distribution of $\mathrm{OH} / \mathrm{H}_{2} \mathrm{O}$ on the surface of the Moon seen by Chandrayaan-1. Science, 2009, 326; doi:10.1126/science. 1178658 .

5. Clark, R. N., Detection of adsorbed water and hydroxyl on the Moon. Science, 2009, 326; doi:10.1126/science.118105.

6. Hampton, D. L. et al., An overview of the instrument suite for the deep impact mission. Space Sci. Rev., 2005, 117, 43-93.

7. Brown, R. H. et al. The Cassini visual and infrared mapping spectrometer (VIMS) investigation. Space Sci. Rev., 2004, 115, 111168 .

8. Murchie, S. L. et al., Compact reconnaissance imaging spectrometer for mars investigation and dataset from the mars reconnaissance orbiter's primary science phase. J. Geophys. Res., 2009, 114, E00D07.

9. Sunshine, J. M. et al., Temporal and spatial variability of lunar hydration as observed by the deep impact spacecraft. Science, 2009, 326, doi:10.1126/science. 1179788 .

10. Goswami, J. N. and Annadurai, M., An overview of the Chandrayaan-1 mission. Curr. Sci., 2009, 96, 486-491.

11. Kumar, A. S. K. et al., Hyperspectral imager for lunar minera mapping in visible and near infrared band. Curr. Sci., 2009, 96, 496.

12. Bhattacharya, S., Majumdar, T. J., Rajawat, A. S., Panigrahi, M. K. and Das, P. R., Utilization of Hyperion data over Dongargarh, India, for mapping altered/weathered and clay minerals along with field spectral measurements. Int. J. Remote Sensing, 2012, 33(17), 5438-5450.

13. Kusuma, K. N., Ramakrishnan, D. and Pandalai, H. S., Spectra pathways for effective delineation of high-grade bauxites: a case study from the Savitri River Basin, Maharashtra, India, using EO-1 Hyperion data. Int. J. Remote Sensing, 2012, 33(22), 72737290 .

14. Magendran, T. and Sanjeevi, S., Hyperion image analysis and linear spectral unmixing to evaluate the grades of iron ores in parts of Noamundi, eastern India. Int. J. Appl. Earth Obs. Geoinf., 2014, 26, 413-426.

15. Rani, N., Mandla, V. R. and Singh, T., Spatial distribution of altered minerals in the Gadag Schist Belt (GSB) of Karnataka, southern India using hyperspectral remote sensing data. Geocarto Int., 2017, 32(3), 225-237.

16. Shanmugam, S. and Abhishekh, P. V., Spectral unmixing of hyperspectral data to map bauxite deposits. In Multispectral, Hyperspectral, and Ultraspectral Remote Sensing Technology, Techniques, and Applications (eds Smith, W. Sr. L. et al.), SPIE, 2006, vol. 6405, pp. 64051N.

17. Thompson, D. R., Boardman, J. W., Eastwood, M. L. and Green, R. O., A large airborne survey of Earth's visible-infrared spectral dimensionality. Opt. Express, 2017, 25(8), 9186-9195.

18. Thompson, D. R. et al., Atmospheric correction with the Bayesian empirical line. Opt. Exp., 2016, 24, 2134-214.

19. Gupta, S. N., Arora, Y. K., Mathur, R. K., Iqballuddin, Prasad, B., Sahai, T. N. and Sharma, S. B., Lithostratigraphic Map of Aravalli region, Southeastern Rajasthan and Northern Gujarat. Geological Survey of India, Hyderabad, 1980.

20. Dey, B., Das, K., Dasgupta, N., Bose, S. and Ghatak, H., Zircon $\mathrm{U}-\mathrm{Pb}$ SHRIMP dating of the Jahazpur granite and its implications on the stratigraphic status of the Hindoli-Jahazpur group. In Seminar Abstract Volume: Developments in Geosciences in the Past Decade-Emerging Trends for the Future and Impact on Society and Annual General Meeting of the Geological Society of India, IIT Kharagpur, 21-23 October 2016.
21. Pandit, M. K., Sial, A. N., Malhotra, G., Shekhawat, L. S. and Ferreira, V. P., C-, O-isotope and whole-rock geochemistry of Proterozoic Jahazpur carbonates. NW Indian Craton. Gondwana Res., 2003, 6(3), 513-522.

22. Geology and Mineral Resources of Rajasthan, Geological Survey of India Miscellaneous Publication No. 30, Part 12, 3rd revised edn, 2011, ISSN 0579-4706.

23. Pelkey, S. M. et al., CRIMS multispectral summary products: parameterizing mineral diversity on Mars from reflectance. J. Geophys. Res., 2007, 112(E8), doi:10.1029/2006JE002831.

24. Viviano-Beck, C. E. et al., Revised CRISM spectral parameters and summary products based on the currently detected mineral diversity on Mars. J. Geophys. Res.: Planets, 2014, 119, 6; doi:10.1002/2014JE004627.

25. Bhattacharya, S., Chauhan, P., Rajawat, A. S., Ajai and Kumar, A. S. K., Lithological mapping of central part of Mare Moscoviense using Chandrayaan-1 Hyperspectral Imager (HySI) data. Icarus, 2011, 211, 470-479.

26. Pieters, C. M., Gaddis, L., Jolliff, B. and Duke, M., Rock types of South Pole-Aitken basin and extent of basaltic volcanism. J. Geophys. Res., 2001, 106, 28001-28022; doi:10.1029/2000JE001414.

27. Crawford, A. R., The Precambrian geochronology of Rajasthan and Bundelkhand, northern India. Can. J. Earth Sci., 1970, 7(1), 91-110.

28. Sharma, N. L. and Nandy, N. C., A note on the petrological classification of the basic intrusives of Danta State (N. Gujarat). Proc. Indian Acad. Sci., 1936, 3, 366-376.

29. Deb, M., Genesis and metamorphism of two stratiform massive sulfide deposits at Ambaji and Deri in the Precambrian of western India. Econ. Geol., 1980, 75(4), 572-591.

30. Mustard, J. F. et al., Compositional diversity and geologic insights of the Aristarchus crater from Moon Mineralogy Mapper data. J. Geophys. Res., Planets, 2011, 116, EOOG12.

31. Clark, R. N. and Roush, T. L., Reflectance spectroscopy: quantitative analysis techniques for remote sensing applications. J. Geophys. Res.: Solid Earth, 1984, 89(B7), 6329-6340.

32. Rodger, A., Laukamp, C., Haest, M. and Cudahy, T., A simple quadratic method of absorption feature wavelength estimation in continuum removed spectra. Remote Sensing Environ., 2012, 118, 273-283.

33. Hunt, G. R. and Salisbury, J. W., Visible and near infrared spectra of minerals and rocks. II. Carbonates. Modern Geol., 1971, 2, 2330 .

34. Gaffey, S. J., Spectral reflectance of carbonate minerals in the visible and near infrared $(0.35-2.55 \mu \mathrm{m})$; calcite, aragonite, and dolomite. Am. Mineral., 1986, 71(1-2), 151-162.

35. Adams, J. B. and McCord, T. B., Optical properties of mineral separates, glass, and anorthositic fragments from Apollo mare samples. In Lunar and Planetary Science Conference Proceedings, 1971, vol. 2, p. 2183.

36. Longhi, J., Walker, D. and Hays, J. F., Fe and Mg in plagioclase. In Lunar and Planetary Science Conference Proceedings, 1976, vol. 7, pp. 1281-1300.

37. Clark, R. N., Spectroscopy of rocks and minerals, and principles of spectroscopy. Man. Remote Sensing, 1999, 3, 3-58.

38. Launeau, P., Girardeau, J., Sotin, C. and Tubia, J. M., Comparison between field measurements and airborne visible and infrared mapping spectrometry (AVIRIS and HyMap) of the Ronda peridotite massif (southwest Spain). Int. J. Remote Sensing, 2004, 25(14), 2773-2792.

39. Guha, A., Ghosh, B., Vinod Kumar, K. and Chowdhary, S., Implementation of reflection spectroscopy based new aster indices and principal components to delineate chromitite and associated ultramafic-mafic complex in parts of Dharwar Craton, India. Adv. Space Res., 2015, 56, 1453-14680.

40. Rajendran, S. et al., ASTER detection of chromite bearing mineralized zones in Semail Ophiolite Massifs of the northern Oman 
Mountains: exploration strategy. Ore Geol. Rev., 2012, 44, 121135 .

41. Cooley, T. et al., FLAASH, a MODTRAN4-based atmospheric correction algorithm, its application and validation. International Geoscience and Remote Sensing Symposium (IGARSS), 2002, 3, 1414-1418.

42. Sultan, S. A., Mansour, S. A., Santos, F. M. and Helaly, A. S., Geophysical exploration for gold and associated minerals, case study: Wadi ElBeida area, South Eastern Desert, Egypt. J. Geophys. Eng., 2009, 6, 345-356.

43. Tontini, F. C., de Ronde, C. E., Scott, B. J., Soengkono, S., Stagpoole, V., Timm, C. and Tivey, M., Interpretation of gravity and magnetic anomalies at Lake Rotomahana: geological and hydrothermal implications. J. Volcanol. Geother. Res., 2016, 314, 8494.

44. Subramaniam, A. P., Mineralogy and petrology of the Sittampundi complex, Salem district, Madras State, India. Geol. Soc. Am. Bull., 1956, 67, 317-390.

45. Windley, B. F., Bishop, F. C. and Smith, J. V., Metamorphosed layered igneous complexes in Archean granulite - gneiss belts. Annu. Rev. Earth Planet. Sci., 1981, 9, 175.

46. Kraut, S., Scharf, L. L. and Butler, R. W., The adaptive coherence estimator: a uniformly most-powerful-invariant adaptive detection statistic. IEEE Trans. Signal Process, 2005, 53(2), 427-438.
47. Murthy, D. S. N. and Dayal, A. M., Geochemical characteristics of kimberlite rock of the Anantapur and Mahbubnagar districts, Andhra Pradesh, South India. J. Asia Earth Sci., 2001, 19, 311319.

48. Arindam, G., Vinod Kumar, K., Ravi, S. and Dhanamjaya Rao, S., Reflectance spectroscopy of kimberlite - in parts of Dharwar Craton, India. Arab. J. Geosci., 2015, 8(11), 9373-9388.

ACKNOWLEDGEMENTS. We thank Shri D. K. Das, Director, Space Applications Centre (SAC; ISRO), Ahmedabad; Shri Santanu Chowdhury, Director, National Remote Sensing Centre (NRSC; ISRO), Hyderabad; Dr Raj Kumar, Dy. Director, Earth, Ocean, Atmosphere, Planetary Sciences and Application Area, SAC, ISRO, Dr P. V. N. Rao, Dy. Director, Remote Sensing Applications Area, NRSC and Dr A. S. Arya, Head, Planetary Sciences Division, SAC, for their valuable guidance and support. We also thank all the team members involved in the AVIRIS-NG mission.

doi: $10.18520 / \mathrm{cs} / \mathrm{v} 116 / \mathrm{i} 7 / 1143-1156$ 